\title{
Microstructure and Shear Strength of Novel Aluminum to Steel Resistance Spot Welds
}

\author{
Multiring domed electrodes produced consistent intermetallic shear strength, \\ which was directly measured using novel mini-shear specimens
}

\author{
BY J. KANG, L. SHI, B. SHALCHI-AMIRKHIZ, D. R. SIGLER, A. S. HASELHUHN, AND B. E. CARLSON
}

\begin{abstract}
Resistance spot welds were produced between dissimilar 1.2-mm-thick wrought aluminum alloy AA6022-T4 and 2.0-mm-thick interstitial free (IF) steel with acceptable joint strength using symmetric and asymmetric electrode combinations that incorporate a multiring domed (MRD) electrode and multiple solidification weld schedules. The focused ion beam and transmission electron microscopy results indicated the intermetallic layer that was created consisted of two distinct layers, i.e., a needle-like $\mathrm{FeAl}_{3}$ adjacent to the AA6022-T4 sheet and a tongue-like $\mathrm{Fe}_{2} \mathrm{Al}_{5}$ adjacent to the IF steel sheet. A new mini-shear test was developed to directly measure the shear strength of the intermetallic layer formed at the interface of these welds produced using symmetric and asymmetric welding electrodes. The results showed the intermetallic layer near the aluminum weld nugget periphery, which is the region critical for joint strength, had an intermetallic layer less than 2 $\mu \mathrm{m}$ thick and an average shear strength of $64 \mathrm{MPa}$, irrespective of the welding electrodes used. In addition, the tensile shear strengths of the aluminum-steel welds were greater than comparable aluminum-aluminum resistance spot welds.
\end{abstract}

\section{KEYWORDS}

- Resistance Spot Weld • Shear Strength • Intermetallic Layer $\bullet$ Microstructure $\bullet$ Mechanical Behavior

\section{Introduction}

Multimaterial structures are becoming more commonplace in the automotive industry to reduce carbon emissions and improve fuel economy. Along with these structures come challenges posed by joining dissimilar materials, and particularly in joining aluminum alloys to steel materials.

There are numerous ways to join automotive body structures, including self-pierce riveting, friction stir welding, laser welding, resistance spot welding (RSW), and adhesive bonding. Resistance spot welding is particularly attractive because it can be used to quickly join a number of different alloys without the additional cost or complexity of rivets, filler materials, or lasers. Resistance spot welding has traditionally been used to join similar alloys, but it can also be used to join dissimilar metals, such as aluminum alloys to steel. Sigler and Carlson (Ref. 1) indicated that spot welding aluminum alloys to steel materials have several unique challenges due to the disparate material properties of the two metals. Aluminum and steel melt at very different temperatures (approximately $600^{\circ}$ vs. $1500^{\circ} \mathrm{C}$, respectively). Thus, the aluminum is molten well before the steel is relatively hot. The aluminum sheet also exhibits an insulating oxide layer that increases the surface contact resistance during spot welding. If these challenges can be surmounted, the melting and solidification of aluminum adjacent to steel results in the formation of aluminum-iron intermetallics with potentially weak material properties. These intermetallic layers can be detrimental to the strength of the interface and any joint that is formed. For example, Qiu et al. used a cover plate to resistance spot weld cross-tension specimens of AA5052 and cold-rolled steel (Ref. 2). Qiu et al. observed the interfacial reaction layer can deteriorate the joint strength when its thickness exceeds $1.5 \mu \mathrm{m}$. These joints produced an interfacial strength of only approximately $6.5 \mathrm{MPa}$ (Ref. 2). Arghavani et al. reported a thicker intermetallic layer of $5.5 \mu \mathrm{m}$ in spot welds comprised of AA5052 to galvanized steel (Ref. 3). In welds comprised of AA5052 to low-carbon steel, Mortazavi et al. observed the 6 - $\mu \mathrm{m}$-thick brittle intermetallic compound (IMC) formed at the interface and acted as an easy crack propagation path, which contributed to high interfacial fracture susceptibility (Ref. 4).

To enable welding of aluminum alloys, an electrode that disrupts outer surface oxide films and minimizes sheetelectrode resistance was used, so that sheet-to-sheet resistance is dominant. Sigler et al. developed a specialized electrode with a series of concentric rings on a domed surface, thus the name multiring domed (MRD) electrode (Refs. 5-7). For welding of aluminum alloys to steel materials, 


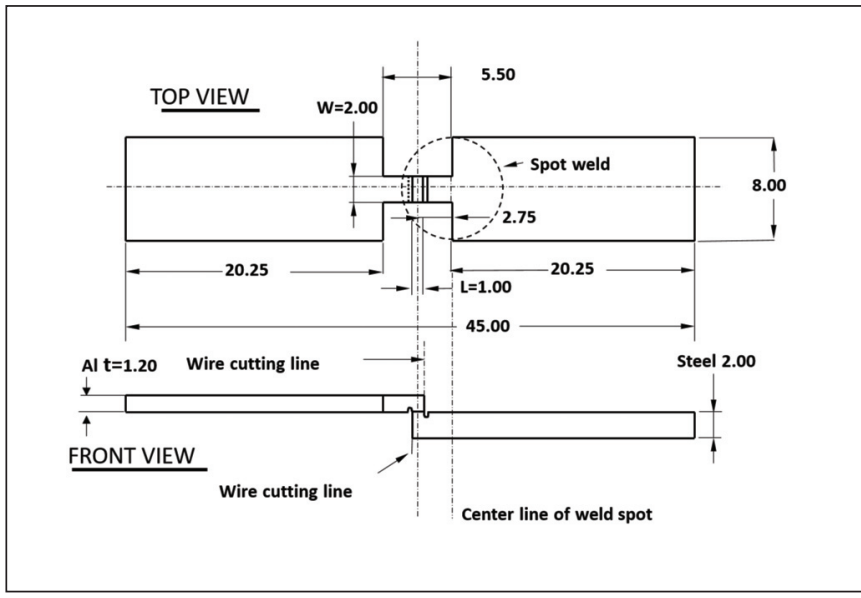

Fig. 1-Mini-shear test specimen design.

Sigler et al. combined the MRD electrode with a multiple solidification welding schedule to successfully weld aluminum alloys to steel materials with acceptable joint strength (Refs. $5,6)$. This welding process does not require the use of prewelding treatment of material surfaces or the use of cover plates such as those used by Qiu et al. (Ref. 2), or interlayers used by Ibrahim et al. (Ref. 8) during welding.

It is well recognized that although the formation of IMCs cannot be completely eliminated during RSW of aluminum alloys to steels, it is possible to minimize the thickness of the intermetallic layer at the interface and improve weld strengths through optimization of the welding process conditions. Zhang et al. developed an optimal electrode design to spot weld AA6008-T66 aluminum alloy and H220YD galvanized high-strength steel that produced an approximately $4.0-\mu \mathrm{m}$ thick intermetallic layer (Ref. 9). However, the alumimum sheets were ground and degreased in acetone prior to welding, which is impractical in a production setting. Ibrahim et al. inserted an 80- $\mu \mathrm{m}$ Al-Mg film between the AA6061 aluminum alloy and 304 steel to reduce the IMC layer thickness to approximately $2 \mu \mathrm{m}$ (Ref. 8).

Other factors can significantly affect joint strength. Both solidification porosity, which is characterized by gas pores, shrinkage voids, and microcracks, as well as remnants of the tough, adherent oxide film that forms on aluminum alloys can accumulate along the faying interface adjacent to the intermetallic layer. Sigler and Carlson suggested these defects can have a much greater impact on joint strength than the intermetallic layer (Ref. 1).

In the present study, symmetric and asymmetric electrode combinations incorporating MRD electrodes were used in combination with multiple solidification weld schedules to weld wrought aluminum alloy AA6022-T4 to hot-dip galvanized, interstitial free (IF) steel sheet in the tensile shear con-
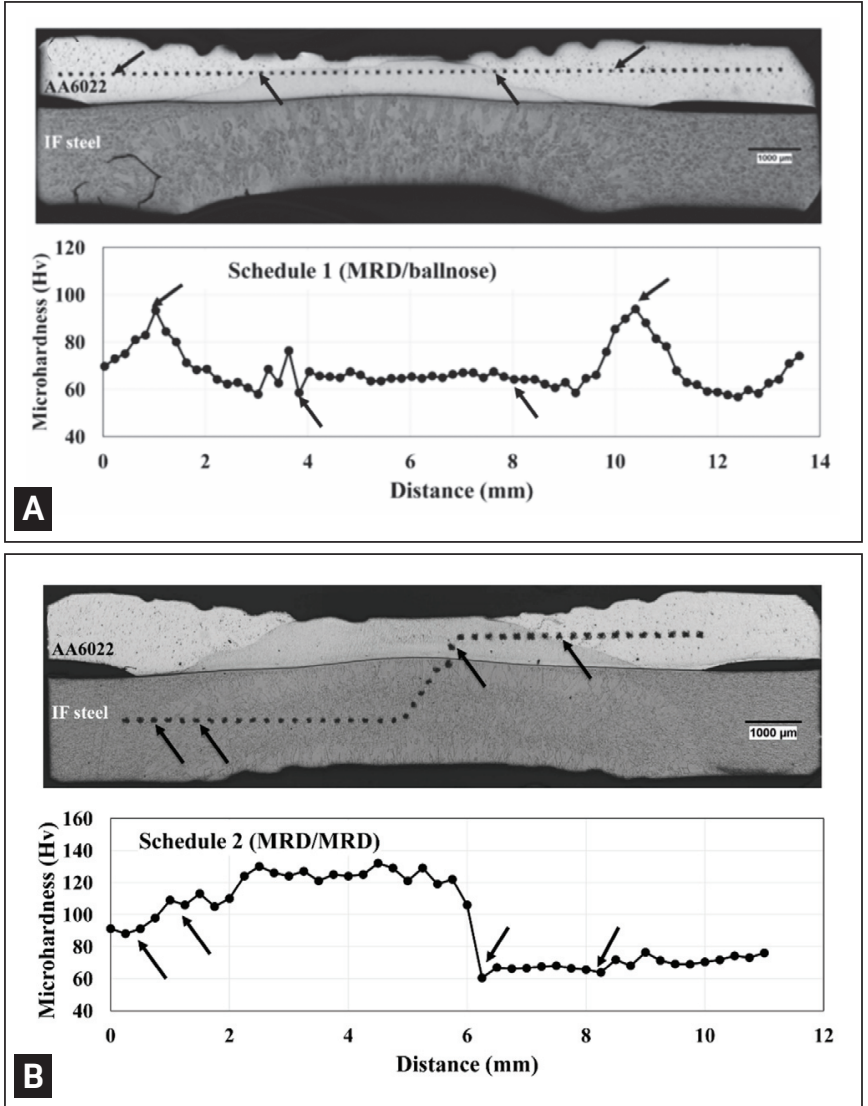

Fig. 2-Macrostructure and microhardness measurements of AA6022-T4 to IF steel resistance spot welds: A - Schedule 1 (MRD/ballnose) as welded; $B$ - Schedule 2 (MRD/MRD) as welded.

figuration. In addition to optical and scanning electron microscopy, focused ion beam (FIB) and transmission electron microscopy (TEM) were used to reveal the structure of the intermetallic layer at the interface. A mini-shear test was developed to directly measure the shear strength of the interface of these welds and establish a quantitative relationship between the microstructure and mechanical property of the interface.

\section{Materials and Experimental Procedure}

\section{Materials}

The materials used in the study included AA6022-T4 wrought aluminum alloy sheet in a thickness of $1.2 \mathrm{~mm}$ and hot-dip galvanized, IF steel in a thickness of $2 \mathrm{~mm}$. The nominal chemical compositions of the two materials are presented in Table 1.

Table 1 - Chemical Composition of AA6022-T4 and IF Steel

\begin{tabular}{cccccccccccccc} 
& $\mathrm{Mg}$ & $\mathrm{Si}$ & $\mathrm{Cu}$ & $\mathrm{Fe}$ & $\mathrm{Mn}$ & $\mathrm{Ti}$ & $\mathrm{Zn}$ & $\mathrm{Cr}$ & $\mathrm{C}$ & $\mathrm{Al}$ & $\mathrm{Ni}$ & $\mathrm{Nb}$ & $\mathrm{P}$ \\
\hline 6022 & 0.50 & 0.64 & 0.21 & 0.19 & 0.12 & 0.043 & 0.018 & 0.016 & - & Balance & - & - & - \\
IF steel & - & 0.0028 & 0.011 & Balance & 0.13 & 0.032 & - & 0.021 & 0.026 & 0.033 & 0.017 & 0.0040 & 0.016
\end{tabular}




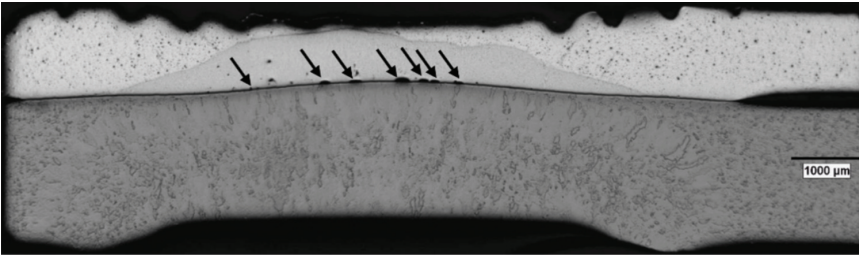

Fig. 3 - Macrostructure of AA6022-T4 to IF steel resistance spot welds from Schedule 1 (MRD/ballnose) after Stage 1 of the weld schedule. Arrows highlight porosity.

\section{Welding}

A medium-frequency direct current (MFDC) pedestal welding machine was used to prepare the spot weld specimens. Welding Technology Corp. (Farmington Hills, Mich.) inverter weld controls, along with RoMan Mfg. Inc. (Grand Rapids, Mich.) MFDC transformers, supplied current to the welding electrodes. Pneumatic actuators were used to apply weld force. Distilled water at ambient temperature was used to cool the welding electrodes at a flow rate of 1.5 to 2.0 $\mathrm{gal} / \mathrm{min}$. All material stackups were welded with $19-\mathrm{mm}-$ diameter CuZr C15000 copper alloy electrodes and with the aluminum sheet contacting the positive electrode.

Two resistance welding schedules (Table 2) were used to weld aluminum-steel tensile shear specimens. It is noted that in Schedule 1 (MRD/ballnose), Sigler et al. (Refs. 10, 11) used an MRD electrode on the aluminum side only and a ballnose electrode on the steel side (asymmetric or hybrid electrodes), while in Schedule 2, MRD electrodes were used on both the aluminum and steel sides of the stackup (symmetric electrodes). The weld schedules were based on the multiple solidification welding template developed by Sigler et al. (Refs. 7, 12). In Stage 1, a large weld nugget was created with considerable penetration into the aluminum alloy sheet. The solidification of the weld nugget also solidified defects along the intermetallic layer that formed between the aluminum and steel. These defects included gas porosity, shrinkage porosity, and microcracking from remnants of oxide film incorporated into the weld nugget. After solidification, current flow was restarted and a relatively thin layer of aluminum melted adjacent to the intermetallic layer incorporating the defects previously described. Upon resolidification, porosity was consolidated close to the nugget center while the oxide film defects were broken up and dispersed within the nugget.

The two aluminum-steel welding schedules were designed to work in combination with the chosen electrodes. Under load, stresses are highest at the notch root of a resist-
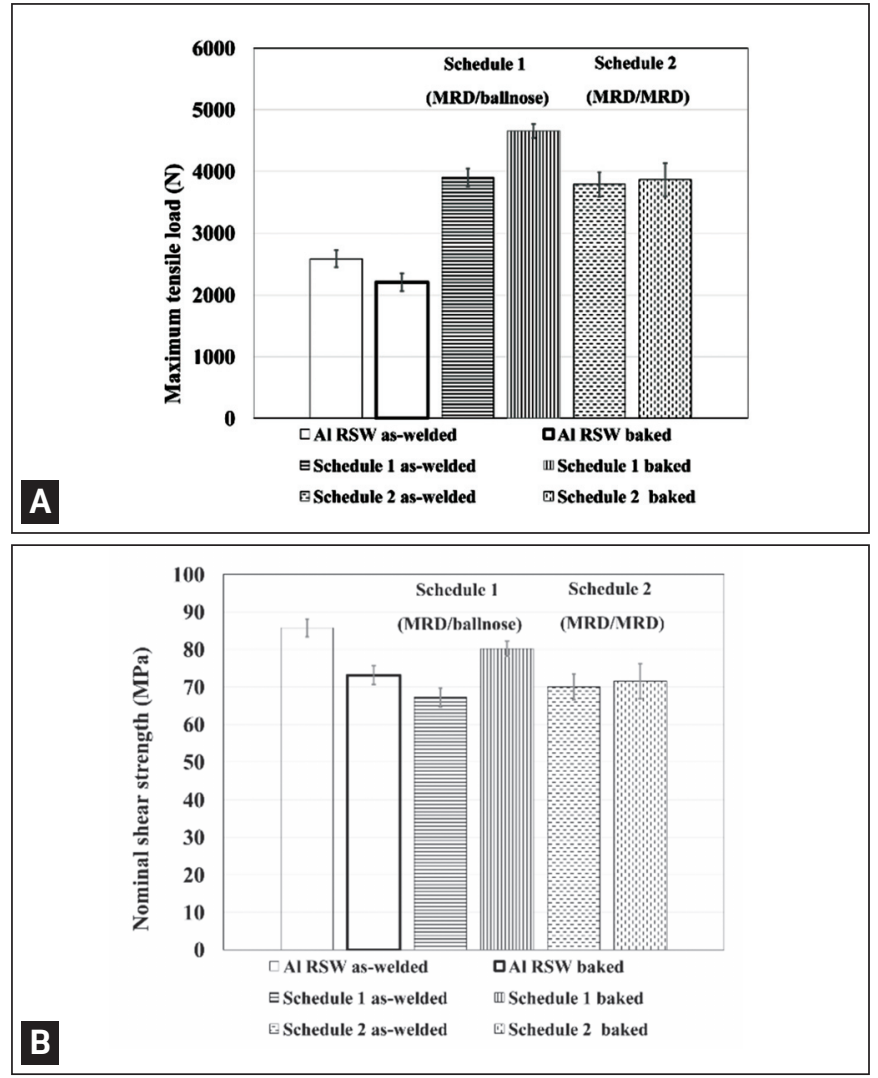

Fig. 4 - AA6022 to IF steel resistance spot weld: A - Average maximum tensile loads; $B$ - normalized tensile-shear strength by weld nugget area. Error bars represent one standard deviation. The strength of tensile-shear samples produced by resistance spot welding 1.2-mm AA6022-T4 to itself is also shown for comparison.

ance spot weld. These weld schedule and electrode combinations were designed to create quality weld nuggets with a thin intermetallic layer along the weld nugget periphery.

As a comparison for tensile shear testing, the $1.2-\mathrm{mm}$ AA6022-T4 sheet material was welded to itself using MRD electrodes, and a weld schedule was developed specifically for spot welding aluminum (Ref. 13). This aluminum weld schedule was designed to initially heat the workpieces to seat the electrodes (conditioning), form the aluminum weld nugget at the faying interface (chaping), and grow the aluminum weld nugget to the desired size (sizing). Weld size was targeted at 5.5 to $6.0 \mathrm{~mm}$, which would represent typical weld sizes in production. After welding, half of the specimens were baked to

Table 2 - Resistance Spot Welding Schedules of 1.2-mm-thick AA6022-T4 to 2.0-mm IF Steel Sheets

\begin{tabular}{|c|c|c|c|c|c|c|c|c|}
\hline Schedule & $\begin{array}{c}\text { Electrodes } \\
\mathrm{Al} / \text { Steel or } \mathrm{Al}-\mathrm{Al}\end{array}$ & $\begin{array}{l}\text { Weld Force } \\
\text { (N) }\end{array}$ & Preheat & $\begin{array}{c}\text { Stage } 1 \\
\text { (rms current) }\end{array}$ & $\begin{array}{l}\text { Stage } 1 \\
\text { (time) }\end{array}$ & $\begin{array}{l}\text { Cool } \\
\text { (time) }\end{array}$ & $\begin{array}{c}\text { Stage } 2 \\
\text { (rms current) }\end{array}$ & $\begin{array}{c}\text { Stage } 2 \\
\text { (time) }\end{array}$ \\
\hline $\begin{array}{c}\text { Al-Steel } \\
\text { Schedule } 1\end{array}$ & MRD/Ballnose & 3114 & $\sim 6 \mathrm{kA}, 40 \mathrm{~ms}$ & $12 \mathrm{kA}$ & $820 \mathrm{~ms}$ & $100 \mathrm{~ms}$ & $13.2 \mathrm{kA}$ & $745 \mathrm{~ms}$ \\
\hline $\begin{array}{c}\text { Al-Steel } \\
\text { Schedule } 2\end{array}$ & MRD/MRD & 3781 & $\sim 6 \mathrm{kA}, 40 \mathrm{~ms}$ & $13 \mathrm{kA}$ & $250 \mathrm{~ms}$ & $500 \mathrm{~ms}$ & $13.4 \mathrm{kA}$ & $905 \mathrm{~ms}$ \\
\hline Al-Al & MRD/MRD & 3114 & $\sim 8.1 \mathrm{kA}, 30 \mathrm{~ms}$ & $31 \mathrm{kA}$ & $22 \mathrm{~ms}$ & $3 \mathrm{~ms}$ & $28.8 \mathrm{kA}$ & $76 \mathrm{~ms}$ \\
\hline
\end{tabular}



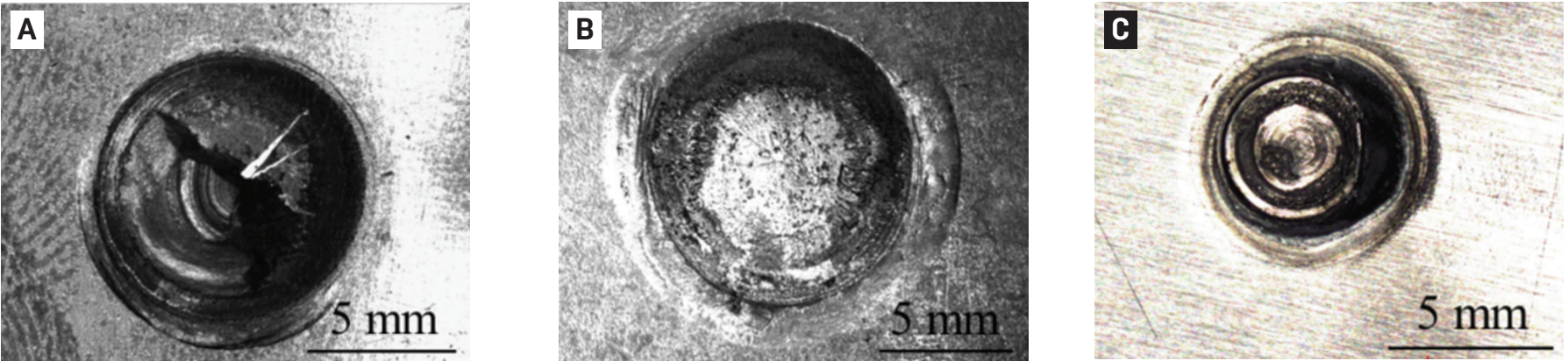

Fig. 5 - Fracture modes: A - AA6022-T4 to IF steel resistance spot welds made using Schedule 1 (MRD/ballnose) and exhibiting partial fracture through the aluminum; B - AA6022-T4 to IF steel resistance spot welds made using Schedule 2 (MRD/MRD) and exhibiting interfacial fracture; $\mathrm{C}$ - aluminum resistance spot weld showing button pullout.

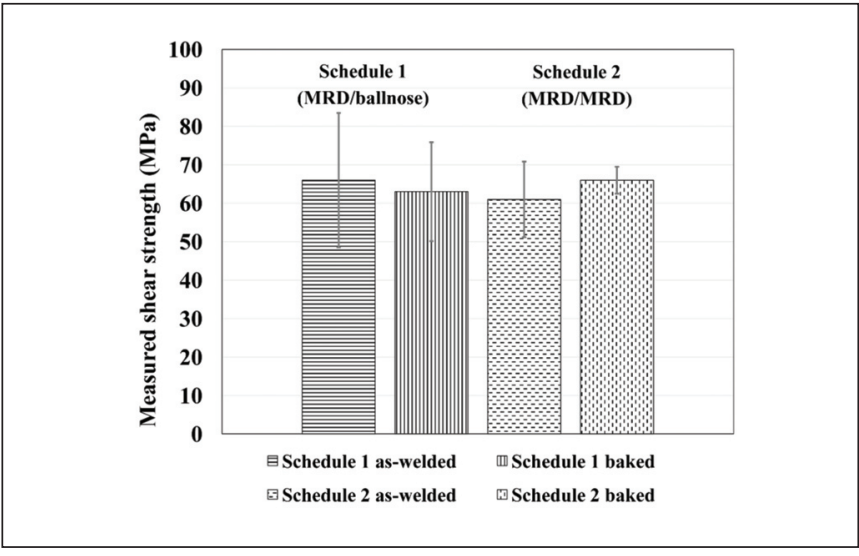

Fig. 6- Measured shear strength of the intermetallic layers in AA6022 to IF steel resistance spot welds. Error bars represent one standard deviation.

simulate the ELPO bake process, which is 35 min holding time at $175^{\circ} \mathrm{C}$.

\section{Metallographic Analysis}

Metallography, optical, and scanning electron microscopy, along with FIB and TEM, were used to reveal the structure of the intermetallic layer at the interface. In addition, microhardness measurements and quasistatic tensile shear testing were performed. The details of these experiments were described in previous studies by Kang et al. (Ref. 14) and Rao et al. (Ref. 15).

\section{Mini-Shear Tests and Analysis}

A novel mini-shear test specimen was designed and presented in Fig. 1. The test was developed to ensure that shear fracture occurred at the interface of the weld nugget without tensile fracture occurring in either the aluminum alloy weld nugget or the heat-affected zone (HAZ), which are the weak locations, i.e.,

$$
L \times W \times \tau_{I M C} \leq W \times t_{A l \text { nugget }} \times \sigma_{\text {Al nugget }}
$$

where $L, W, t_{\text {Al nugget }}, \tau_{I M C}$, and $\sigma_{A l \text { nugget }}$ are the length and width of the shear zone, thickness of the aluminum weld nugget, shear strength of the intermetallic layer, and tensile

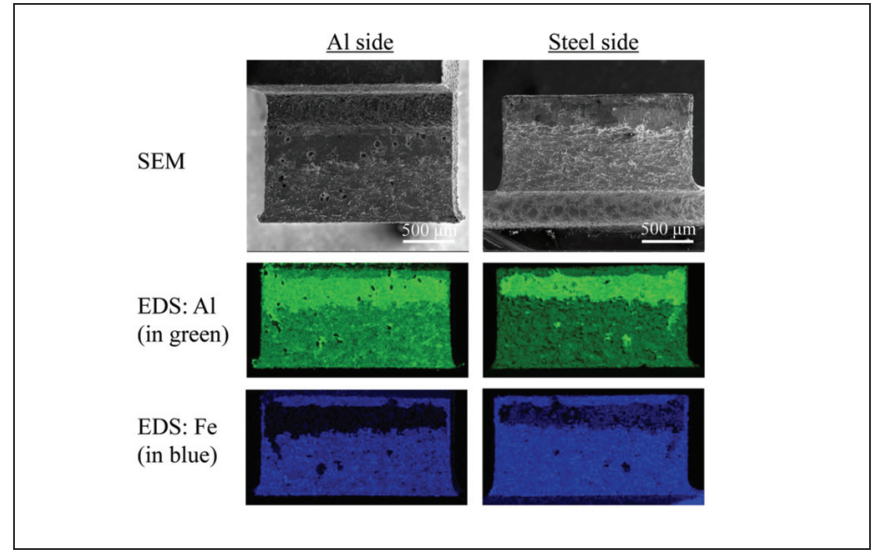

Fig. 7-EDS maps of Al and Fe of fractured surfaces of an AA6022 to IF steel resistance spot weld produced using Schedule 2 (MRD/MRD).

strength of the aluminum nugget, respectively.

Assuming isotropy and von Mises yield criterion for the intermetallic layer and rearranging Equation 1 gives

$$
\begin{aligned}
& L \leq \frac{\sigma_{\text {Al nugget }}}{\tau_{\text {IMC }}} t_{A l \text { nugget }}=\sqrt{3} \frac{\sigma_{\text {Al nugget }}}{\sigma_{I M C}} t_{A l \text { nugget }} \\
& =(1-\alpha) \frac{\sigma_{A l \text { nugget }}}{\sigma_{I M C}} \sqrt{3} t_{A l} \approx(1-\alpha) \sqrt{3} t_{A l}
\end{aligned}
$$

where $\alpha=0.10-0.15$ is the indentation ratio, i.e., the thickness reduction in the aluminum side for the MRD electrode, $\sigma_{I M C}$ is the tensile strength of the intermetallic layer, and $\sigma_{A l}$ ${ }_{\text {nugget }} / \sigma_{I M C}$ is usually greater than 1 , i.e., the tensile strength of the aluminum weld nugget is greater than that of the intermetallic layer. The strength of the aluminum weld nugget is dependent, in part, on the thickness of the aluminum nugget. During spot welding, the aluminum deforms and "indents" as heat is applied, reducing the aluminum thickness. This indentation was approximated as $\alpha$. Thus, the final result in Equation 2, $(1-\alpha) \sqrt{3} t_{A l}$, gives a more conservative estimation of the shear zone length $L$.

Based on Equation 2, $W=2 \mathrm{~mm}$ and $L=1 \mathrm{~mm}$ were chosen for the shear zone size of all the mini-shear test specimens used in the present study where $t_{A l}$ is $1.2 \mathrm{~mm}$. The mini-shear specimens were prepared using wire electrical discharge ma- 
A

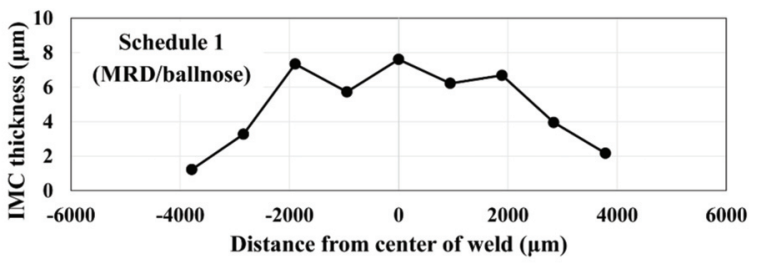

B

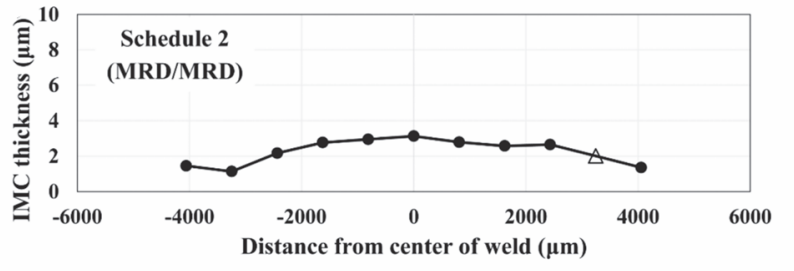

Fig. 8 - Intermetallic profile as measured by light optical microscopy for the AA6022-T4 to IF steel resistance spot welds: A - Schedule 1 (MRD/ballnose); $B$ - Schedule 2 (MRD/MRD). Filled symbols indicate no defects in the aluminum nugget near the intermetallic layer, and the open triangular symbol indicates $\sim 100 \%$ of the aluminum interface near the intermetallic layer contained defects.

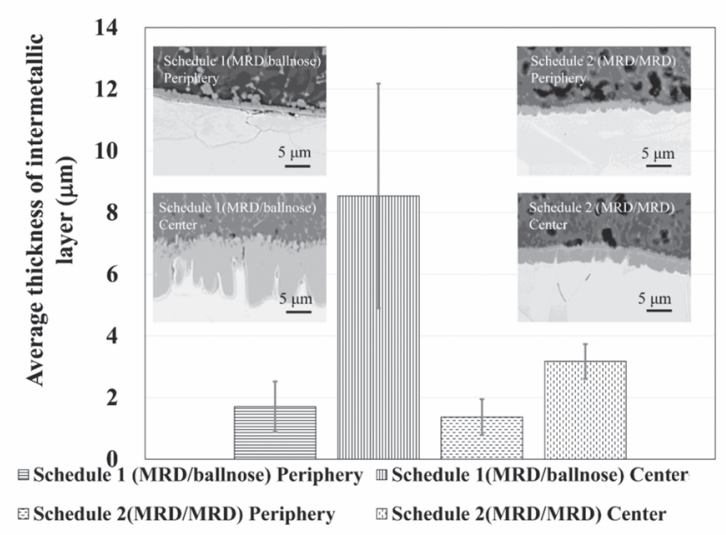

Fig. 9-Measured intermetallic thickness in the center and at the periphery of the AA6022-T4 to IF steel resistance spot welds. Error bars represent one standard deviation.

chining. Since the high stress region is at the weld nugget periphery adjacent to the notch root, the shear zone $(2 \times 1 \mathrm{~mm})$ was entirely positioned at that location for all the resistance spot welds tested.

The mini-shear test specimens were loaded in tension using a standard MTS LandMark ${ }^{\circledR} 370$ load frame with a 5-kN load cell at a rate of $0.3 \mathrm{~mm} / \mathrm{min}$ until specimen fracture occurred. After mini-shear testing, specimens were collected for fractography and energy dispersive spectroscopy (EDS) mapping completed on both the aluminum and steel sides using a field emission scanning electron microscope (FESEM).

\section{Experimental Results}

\section{Macrostructure and Microhardness}

Figure 2A, B are macrostructure images and the associated microhardness measurements of AA6022-T4 to IF steel resistance spot welds using two different multiple solidification welding schedules. The welds in this study exhibited structures that are typical for aluminum-steel (Al-steel) resistance spot welds as described by Sigler and Carlson (Ref. 1). Al-steel resistance spotwelds exhibited a planar interface with a large aluminum weld nugget that wets the steel surface, which is consistent with the results shown in Sigler and Carlson (Ref. 1). Defects such as gas porosity, shrinkage porosity, or cracking were not observed within the aluminum weld nugget. Figure 3 is a macrostructure image of a joint produced by interrupting the full, multistage weld schedule, Schedule 1 (MRD/ballnose), following Stage 1 and before Stage 2 of the weld schedule. The arrows highlight the interfacial porosity at the faying interface after Stage 1. This porosity is not evident in the macrostructure presented in Fig. 2, which shows a weld structure after both Stage 1 and 2 of the weld schedule. This demonstrates the effectiveness of the complete two-stage multiple solidification weld schedule in consolidating and eliminating porosity near the faying interface. A thin, continuous layer of intermetallic compounds formed at the faying interface between the aluminum and steel sheets. From Fig. 2, the average nugget diameter at the faying interface was measured to be 8.6 and $8.3 \mathrm{~mm}$ for AA6022-T4 to IF steel resistance spot welds using Schedule 1 and 2, respectively.

\section{Maximum Tensile Loads}

The average maximum tensile loads are directly compared to the nominal shear strength in Fig. 4. To calculate the nominal shear strength, the average maximum tensile loads were normalized by the weld nugget area using the weld nugget diameter from tensile shear tests of the welded AA6022-T4 to IF steel RSW stackups. The Al-steel resistance spot welds exhibited greater average maximum tensile loads than the analogous $\mathrm{Al}$ resistance spot welds. This is due, in part, to the larger aluminum nugget diameters $(8-9 \mathrm{~mm})$ that develop in Al-steel welds as compared to the standard, smaller Al RSW nugget diameters $(5-6 \mathrm{~mm})$. It is difficult to grow $\mathrm{Al}$ resistance spot welds to the larger nugget diameters due to aluminum's increased electrical and thermal conductivities, which leads to an increased propensity for internal expulsion with increasing current and weld time. Furthermore, to meet requirements for fatigue and other configurations of static mechanical tests, i.e., coach peel and cross tension, $\mathrm{Al}$-steel resistance spot welds require larger nugget diameters than $\mathrm{Al}$ resistance spot welds or even those outlined for steel resistance spot welds $(d=4 \sqrt{t})$ in Ref. 16. This is due to the fact that, in Al-steel resistance spot welds, the weld nugget is contained only within the aluminum sheet and is separated from the steel sheet by a layer of intermetallics; there is no mixing of metal between the aluminum and steel sheets. Thus, it is necessary to have a greater load bearing area in $\mathrm{Al}$-steel resistance spot welds to achieve acceptable strengths. Growing large aluminum nuggets in Al-steel resistance spot welds is relatively easy due to the resistive heat that is developed within the steel sheet. Once normalized for weld diameter, the $\mathrm{Al}$-steel and $\mathrm{Al}$ resistance spot welds exhibited approximately equivalent nominal shear strengths. The baked Al-steel resistance spot welds from Schedule 1 


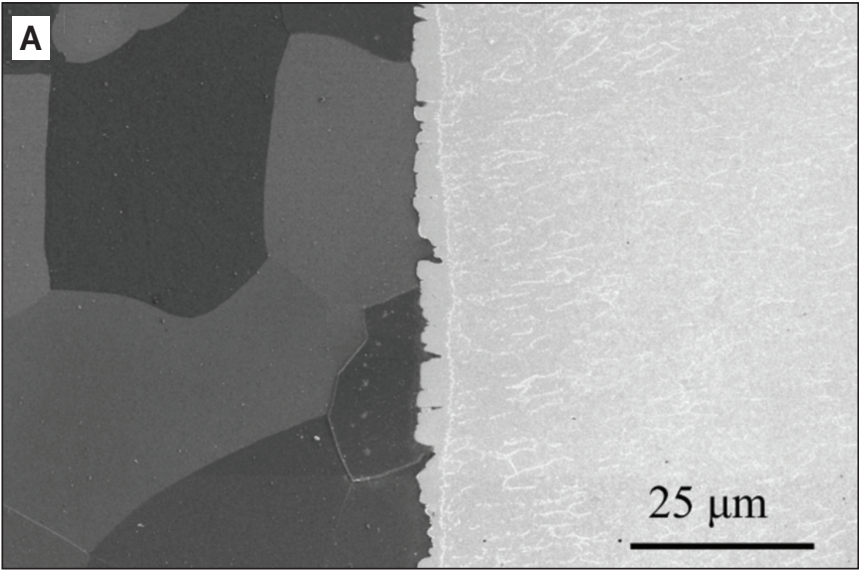

Fig. $10-A A 6022$ to IF steel interface at the periphery of the weld nugget produced using Schedule l: A - FIB image; B EDS maps in TEM.

(MRD/ballnose) exhibited slightly higher nominal shear strength $(81 \mathrm{MPa})$ than the Schedule 2 welds (70 MPa). This was attributed to partial fracture occurring through the aluminum for Schedule 1 welds, whereas interfacial fracture occurred for Schedule 2 welds - Fig. 5. Similar spot welds produced in the 1.2-mm-AA6022-T4 sheet showed a nominal shear strength of $\sim 86 \mathrm{MPa}$ unbaked and $73 \mathrm{MPa}$ baked. This difference is also primarily due to the different fracture modes.

\section{Shear Strength of Intermetallic Layer}

Figure 6 compares the measured shear strength of the intermetallic layer formed at the interface of the Al-steel welds under the two different welding conditions. These results were taken from the perimeter of the weld nugget (refer to Fig. 1). The results show the intermetallic layer had an average shear strength of $64 \mathrm{MPa}$ irrespective of welding condition. The results of EDS maps of fracture surfaces of the tested mini-shear specimens (Fig. 7) confirmed that fracture occurred within the intermetallic layer; thus, the measured strength was indeed the strength of the intermetallic layers.

\section{Discussion}

\section{Advantages of Mini-Shear Specimens}

There is presently no standard procedure to directly measure the shear strength of aluminum to steel resistance spot welds. The traditional method is to report the maximum load capacity in tensile shear tests or nominal shear strength, i.e., the maximum load normalized by weld nugget area. However, this method is only valid if an interfacial fracture occurs at the interface without deformation of the weld nugget and the method is convoluted by the fact that the weld nugget diameter is unknown before testing. In scenarios where only partial fracture occurs through the aluminum sheet, as shown in Fig. 5 , the measured nominal shear strength is invalid because the local stress status is not simple shear anymore. As seen in Fig. 4 , the nominal shear strength of the as-received specimen using Schedule 1 (MRD/ballnose) (80 MPa) appears to be higher than that measured using mini-shear specimens (64 MPa).
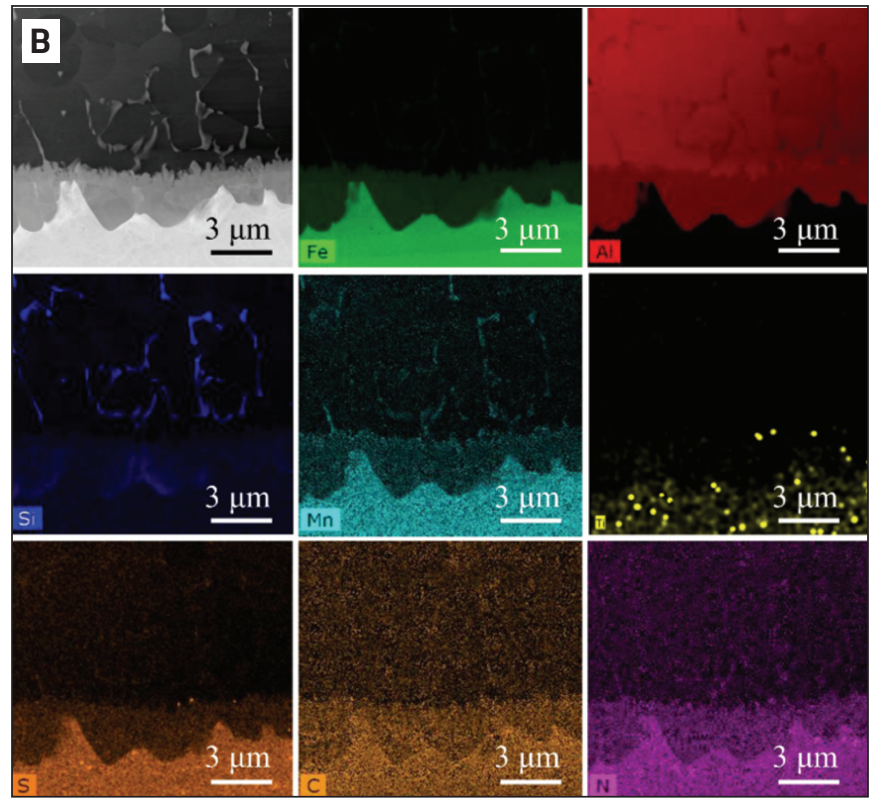

Chen et al. used a specially designed shear jig to test interfacial strength (Ref. 17). Significant difficulties were encountered trying to align the test jig and the interface, leading to fracture often occurring somewhere other than at the interface, particularly for specimens with a thin intermetallic layer. The minishear test method proposed in the present study overcame these disadvantages and directly measured the shear strength of the intermetallic layer with good repeatability.

\section{Effects of Electrodes on the Intermetallic Thickness}

Schedule 1 welds (MRD/ballnose) exhibited a greater degree of scatter in the measured intermetallic shear strengths than Schedule 2 welds (MRD/MRD) (refer to Fig. 6), although similar average shear strengths were obtained for both schedules. The similarity in average shear strengths with the different degree of scatter are attributed to the morphology and thickness distribution of the intermetallic layers. Figure 8 shows the intermetallic profiles of the two welds as measured by light optical microscopy. Filled symbols indicate an interface area without any defects as previously described, while the open triangular symbols indicate that 100\% of the interface was compromised by defects. These defects are not contained within the intermetallic layer itself and instead are observed in the aluminum nugget in the region near the intermetallic layer. The presence or absence of defects in the aluminum near the intermetallic layer can influence the intermetallic thickness by acting as a diffusion barrier; thus, it is important to characterize these defects. Both weld schedules produced quality, defect-free interfaces with thin intermetallic layers along the nugget perimeter. Schedule 2 using the MRD/MRD electrode combination produced an overall much thinner intermetallic layer than Schedule 1, which used the $\mathrm{MRD} /$ ballnose electrode combination. The asymmetrical $\mathrm{MRD} / \mathrm{ballnose}$ electrodes modified the current density at the faying interface between the aluminum and steel sheets. The increased current density created more localized heat, which encouraged the growth of the intermetallic layer. 

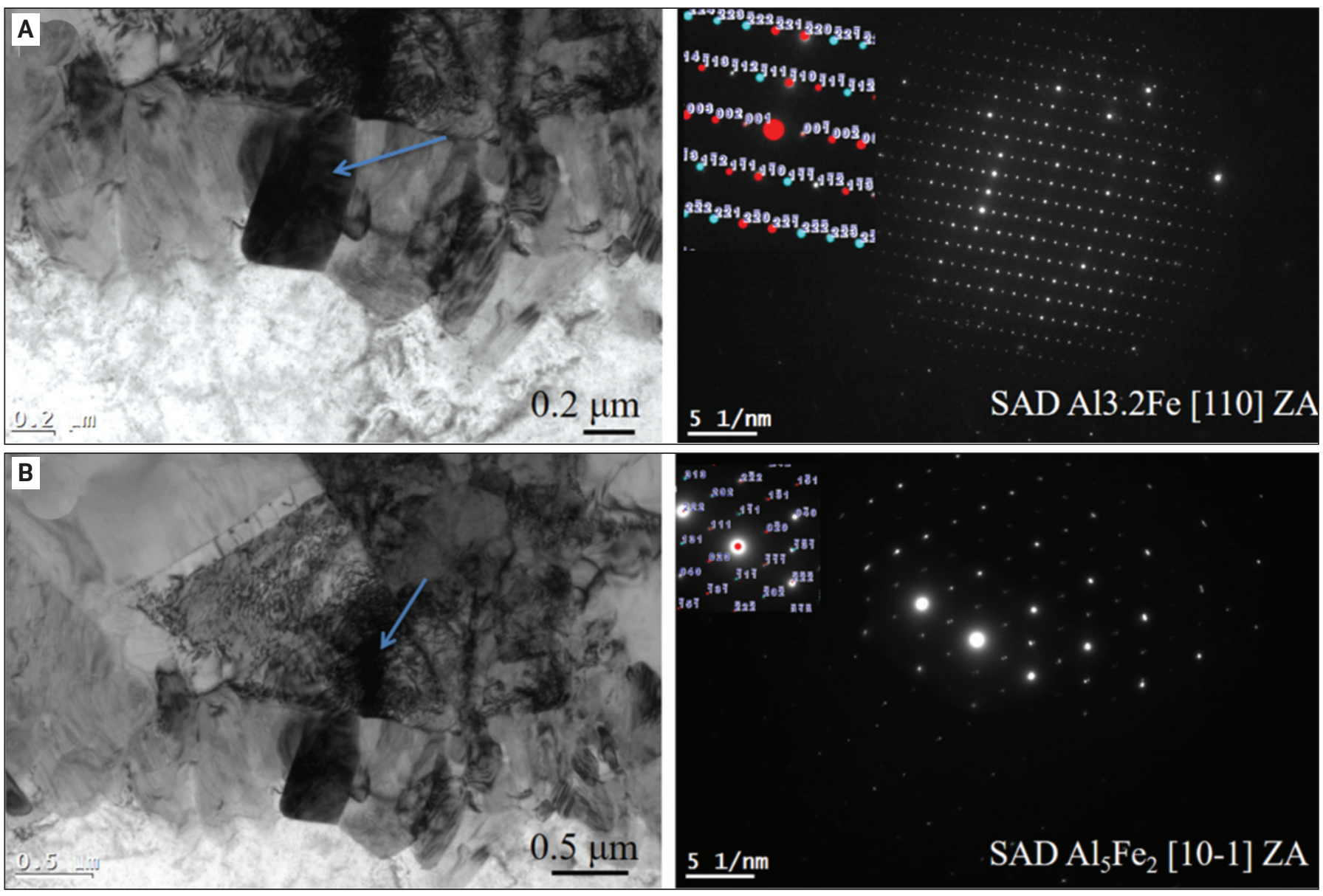

Fig. 11 - TEM results of specimen from Fig. 10 showing a crystallographic structure of: $A$ - The smaller, needle-like intermetallic layer, $\mathrm{FeAl}_{3}$; $\mathrm{B}$ - the larger, tongue-like intermetallic layer, $\mathrm{Fe}_{2} \mathrm{Al}_{5}$. The blue arrows point to evidence of strain (discolorations) within the intermetallic layer.

The thickness of the intermetallic layers as measured by FESEM analysis of the resistance spot welds is plotted in Fig. 9 , and agrees well with the data from light optical microscopy presented in Fig. 8. From both Figs. 8 and 9, the effect of lower heat and increased lateral solidification at the edges of the weld produced thinner intermetallic layers in this region. By contrast, the intermetallic was thicker in the center of the weld where solidification occurs last; Chen et al. and Qiu et al. concluded there was sufficient heat and time for diffusion to grow the intermetallic layer (Refs. 2, 18). This effect was more pronounced for specimens produced using Schedule 1 (MRD/ballnose) as this electrode combination concentrates more heat in the center of the weld.

\section{Intermetallic Characterization}

As is typical of Al-steel spot welds, an intermetallic bilayer formed that included $\mathrm{FeAl}_{3}$ adjacent to the aluminum and $\mathrm{Fe}_{2} \mathrm{Al}_{5}$ adjacent to the steel, which is in agreement with the results obtained by Wan et al. (Ref. 19) - Fig. 10A. Silicon enrichment was also observed in the aluminum weld nugget near the intermetallic layer (refer to Fig. 10B), which may have acted to limit diffusion and growth of the intermetallic layer. Transmission electron microscopy results confirmed the crystallographic structure of the smaller intermetallic layer, a needle-like $\mathrm{FeAl}_{3}$ (Fig. 11A), and a larger tongue-like intermetallic layer, $\mathrm{Fe}_{2} \mathrm{Al}_{5}$ (Fig. 11B), at the interface of AA6022 to IF steel resistance spot weld from Fig. 10.

\section{Effect of Intermetallic Thickness on Shear Strength Response}

A 2- $\mu \mathrm{m}$-thick intermetallic layer at the weld nugget periphery was produced using either of the two weld schedule and electrode combinations. Furthermore, the symmetrical electrode combination of Schedule 2 (MRD/MRD) produced a much more uniform intermetallic layer shear-strength response compared to the asymmetrical electrode combination of Schedule 1 (MRD/ballnose), indicating that Schedule 2 (MRD/MRD) produced a more consistent quality joint. The increased scatter observed for Schedule 1 (MRD/ballnose) may be due to the resulting intermetallic profile (see Fig. 8). The mini-shear test specimen configuration shown in Fig. 1 was designed to sample the intermetallic layer near the nugget periphery. Since the Schedule 1 (MRD/ballnose) electrode combination produced a steeper gradient of intermetallic thickness near the nugget periphery than the more uniform intermetallic layer produced by Schedule 2 (MRD/MRD), the shear test may have sampled areas containing a thicker intermetallic layer and produced greater spread in the strength data. 


\section{Conclusions}

Resistance spot welds were produced between dissimilar 1.2-mm-thick wrought aluminum alloy AA6022-T4 and 2.0mm-thick hot-dip galvanized, IF steel using a MRD electrode and multiple solidification weld schedules. In tensile-shear configurations, the joints produced acceptable joint strength compared to AA6022-T4 welded to itself. The following conclusions can be drawn:

1) Asymmetric and symmetric electrode combinations resulted in distinctively different intermetallic thickness profiles. The thinnest and most uniform profile was obtained using the symmetric MRD electrode on both the aluminum alloy and steel sheet; this led to improved joint quality and much less scatter in shear-strength data distribution.

2) FIB and TEM results indicated the intermetallic layer consisted of two distinct layers, a needle-like $\mathrm{FeAl}_{3}$ adjacent to the AA6022-T4 sheet and a tongue-like $\mathrm{Fe}_{2} \mathrm{Al}_{5}$ adjacent to the IF steel sheet.

3) A new mini-shear test was successfully developed to directly measure the shear strength of the intermetallic layer formed at the interface of these welds under different welding conditions.

4) The intermetallic layer exhibited an average shear strength of $64 \mathrm{MPa}$ irrespective of welding conditions for intermetallic layers less than $2 \mu \mathrm{m}$ thick at the weld periphery.

\section{Acknowledgments}

The authors gratefully acknowledge the financial support from the Canadian Federal Government Energy Innovation Program, General Motors Canada, and CanmetMATERIALS, Natural Resources Canada. The authors are grateful for help from Jean Paul Talon, Jie Liang, Harish Rao, Pei Liu, Jian Li, and Ruby Zhang on various aspects of the experimental work. Liting Shi thanks the support of her supervisor in China, Professor Xu Chen, and the financial support from China Scholarship Council and CanmetMATERIALS for her stay at CanmetMATERIALS, Hamilton, Ontario, Canada.

\section{References}

1. Sigler, D. R., and Carlson, B. E. 2018. Impediments to developing resistance spot welding processes for joining aluminum to steel. Proceedings of AWS SMWC XVIII.

2. Qiu, R., Iwamoto, C., and Satonaka, S. 2009. Interfacial microstructure and strength of steel/aluminum alloy joints welded by resistance spot welding with cover plate. Journal of Materials Processing Technology 209: 4186-4193. DOI: 10.1016/j.jmatprotec. 2008.11.003

3. Arghavani, M. R., Movahedi, M., and Kokabi, A. H. 2016. Role of zinc layer in resistance spot welding of aluminium to steel. Materials \& Design 102: 106-114. DOI: 10.1016/j.matdes. 2016.04.033

4. Mortazavi, S. N., Marashi, P., Pouranvari, M., and Masoumi, M. 2011. Investigation on joint strength of dissimilar resistance spot welds of aluminum alloy and low carbon steel. Advanced Materials Research 264-265: 384-389. DOI: 10.4028/ www.scientific.net/AMR.264-265.384

5. Sigler, D. R., Carlson, B. E., Myasnikova, Y., and Karagoulis,
M. J. 2018. Multi-Step Direct Welding of an Aluminum-Based Workpiece to a Steel Workpiece, U.S. Patent 9,999,938.

6. Sigler, D. R., Carlson, B. E., and Karagoulis, M. J. 2017. MultiStage Resistance Spot Welding Method for Workpiece Stack-up Having Adjacent Steel and Aluminum Workpieces, U.S. Patent Application 20170106466.

7. Sigler, D. R., Carlson, B. E., Myasnikova, Y., and Karagoulis, M. J. 2015. Multi-Step Direct Welding of an Aluminum-Based Workpiece to a Steel Workpiece, U.S. Patent Application 20150053655.

8. Ibrahim, I., Ito, R., Kakiuchi, T., Uematsu, Y., Yun, K., and Matsuda, C. 2016. Fatigue behaviour of Al/steel dissimilar resistance spot welds fabricated using $\mathrm{Al}-\mathrm{Mg}$ interlayer. Science and Technology of Welding and Joining 21: 223-233. DOI: 10.1179/ 1362171815Y.0000000086

9. Zhang, W., Sun, D., Han, L., and Li, Y. 2015.Optimised design of electrode morphology for novel dissimilar resistance spot welding of aluminium alloy and galvanised high strength steel. Materials and Design 85: 461-470. DOI: 10.1016/j.matdes.2015.07.02.

10. Sigler, D. R., Schroth, J. G., Carlson, B. E., Myasnikova, Y., and Yang, D. 2015. Aluminum Alloy to Steel Welding Process, U.S. Patent Application 20150096962

11. Sigler, D. R., Carlson, B. E., and Karagoulis, M. J. 2017. Welding Electrode Cutting Tool and Method of Using the Same, U.S. Patent Application 20170225262.

12. Sigler, D. R., Carlson, B. E., and Karagoulis, M. J. 2017. Multi-Stage Resistance Spot Welding Method for Workpiece Stackup Having Adjacent Steel and Aluminum Workpieces, U.S. Patent Application 20170206466.

13. Sigler, D. R., Carlson, B. E., and Karagoulis, M. J. 2018. Weld Schedule for Resistance Spot Welding of Aluminum Alloy Workpieces, U.S. Patent 9,969,026 B2.

14. Kang, J., Rao, H. M., Sigler, D. R., and Carlson, B. E. 2017. Tensile and fatigue behaviour of AA6022-T4 to IF steel resistance spot welds. Procedia Structural Integrity 5: 1425-1432. DOI: 10.1016/j.prostr.2017.07.207

15. Rao, H. M., Kang, J., Shi, L., Sigler, D. R., Carlson, B. E. 2018. Effect of specimen configuration on fatigue properties of dissimilar aluminum to steel resistance spot welds. International Journal of Fatigue 116: 13-21. DOI: 10.1016/j.ijfatigue. 2018.06.009

16. AWS D8.1M:2013, Specification for Automotive Weld QualityResistance Spot Welding of Steel. Miami, Fla.: American Welding Society.

17. Chen, J., Li, J., Shalchi-Amirkhiz, B., Liang, J., and Zhang, R. 2014. Formation of nanometer scale intermetallic phase at interface of aluminum-to-steel spot joint by welding-brazing process. Materials Letters 137: 120-123. DOI: 10.1016/j.matlet.

2014.08.102

18. Chen, N., Wang, H. P., Carlson, B. E., Sigler, D. R., and Wang, M. 2018. Fracture mechanisms of $\mathrm{Al} /$ steel resistance spot welds in coach peel and cross tension testing. Journal of Materials Processing Technology 252: 348-361. DOI: 10.1016/j.jmatprotec.2017.09.035

19. Wan, Z., Wang, H. P., Chen, N., Wang, M., and Carlson, B. E. 2017. Characterization of intermetallic compound at the interfaces of Al-steel resistance spot welds. Journal of Materials Processing Technology 242: 12-23. DOI: 10.1016/j.jmatprotec.2016.11.017

JIDONG KANG (jidong.kang@canada.ca), LITING SHI, and BABAK SHALCHI-AMIRKHIZ are with CanmetMATERIALS, Hamilton, Ont., Canada. SHI is also with the School of Chemical Engineering and Technology, Tianjin University, Tianjin, China. DAVID R. SIGLER, AMBERLEE S. HASELHUHN, and BLAIR E. CARLSON are with General Motors Global R\&D Center, Warren, Mich. 